\title{
Study on Approaches of Land Suitability Evaluation for Crop Production Using GIS
}

\author{
Linyi Li, Jingyin Zhao, and Tao Yuan \\ Shanghai Academy of Agricultural Sciences, China \\ linyi_li@hotmail.com
}

\begin{abstract}
In this paper, an approach to assessing ecological suitability of crop growth was developed using GIS, through a case study of maize planting in Jilin Province, in the northeast China, in order to improve the accuracy and objectivity of the evaluation, promote the rationality of crop distribution, and increase the efficiency of the agro-resource utility. Climate and soil conditions in the region were taken into consideration in the research. The crop potential productivity under the climatic condition of 46 meteorological stations in the region, namely photo-temperature-water climatic potential productivity, was calculated based on the meteorological data of the precipitation, temperature, wind speed and sunshine hours from 1980 to 2006, and the crop potential productivity was used as index to evaluate the climatic suitability for crop growth. The point data were interpolated in a GIS environment and formed climatic suitability map. The assessment of soil suitability for crop growth was derived from soil fertility map drawing on the basis of information on 12 parameters, such as terrain, depth of soil body, thickness of black earth, soil erosion and organic mater. The ecological suitability map is completed using methods of spatial overlay in GIS. Comparing with the crop yield map that based on the statistical yield of 30 years in each county, the result of ecological suitability assessment is consistent with the yield. Therefore this method is feasible to assess the ecological suitability in the region.
\end{abstract}

Keywords: Land Suitability Evaluation, Crop Production, Climatic Potential Productivity, Grid Segmentation, GIS.

\section{Introduction}

Land suitability evaluation is the process of assessment of land performance when land is used for specified purposes. Adaptation of crop growth to the potentialities and constraints of local agroecologies is a key principle of sustainable land management. The principal objective of land evaluation is to select the optimum land use for each defined land unit and the conservation of environmental resources for future use. Detailed objectives can vary considerably according to the purpose and scale of land evaluation[1].

Large area lands are used for grain crop production in the northeastern China. The degree of land suitability for crop production is quite different by reason of the diversity of climate, complexity of soil and variety of terrain. Land suitability is the fitness 
of a given type of land for a defined use, but large-scale crop production can not arrange optimum crop for each land unit. Proper land suitability classification approaches are needed to meet the demand of evaluating land suitability for crop growth and large-scale crop production management.

Photo-temperature-water climatic potential productivity, calculated based on the meteorological data of the precipitation, temperature, wind speed and sunshine hours, etc., was taken as indicator for climatic suitability evaluation, and soil fertility composite index based on terrain, depth of soil body, thickness of black earth, soil erosion, organic mater, etc. was taken as index for soil suitability evaluation. Taking maize production in Jilin province as a case study, this research brought forward an approach to evaluating land suitability for large-scale crop production using the spatial analysis and overlay function of geographic information system.

\section{Methods}

\subsection{Index and Method for Climatic Suitability Evaluation}

The crop climatic potential productivity (photo-temperature-water potential productivity) is the highest theoretical productivity of the crop when crop makes full use of the present climatic resources in this area with the most appropriate technology and managerial techniques. The climatic potential productivity is not the real productivity in the area, but it could be taken as the indicator for evaluating climatic suitability for crop production. The higher the climatic potential productivity is, the more suitable the climate in the area is for the crop growth.

Climatic potential productivity was calculated by the formula as follows [5]:

$$
Y=f(Q) f(T) f(W)
$$

Where:

$\mathrm{Y}$ is Climatic potential productivity

$\mathrm{f}(\mathrm{Q})$ is photosynthetic productivity and is the utmost productivity of the crop when crop makes full use of solar radiation in this area with the most suitable temperature, water, soil fertility, technology and managerial techniques.

$$
f(Q)=\sum Q \varepsilon a(1-\rho)(1-\gamma) \Phi(1-\omega)(1-X)^{-1}(1-H)^{-1}
$$

$\Sigma \mathrm{Q}$ is total radiation per unit area and per unit time casting on the area, $\varepsilon$ is the ratio of photosynthetically Active Radiation(PAR) to total solar radiation, $\alpha$ is plant absorption rate for PAR, pis absorption rate of nonphotosynthesis organs, ris limitation rate of photosaturation, $\Phi$ is quantum efficiency, $\omega$ is loss rate of respiration, $\mathrm{X}$ is ash content in the product harvested, $\mathrm{H}$ is water content in the product harvested.

$\mathrm{f}(\mathrm{T})$ is temperature reversionary function

$$
f(T)=\left\{\begin{array}{lr}
0.027 T-0.162 & 6^{\circ} \mathrm{C} \leq T<21^{\circ} \mathrm{C} \\
0.086 T-1.41 & 21^{\circ} \mathrm{C} \leq T<28^{\circ} \mathrm{C} \\
1.00 & 28^{\circ} \mathrm{C} \leq T<32^{\circ} \mathrm{C} \\
-0.083 T & 32^{\circ} \mathrm{C} \leq T<44^{\circ} \mathrm{C} \\
0 & T<6^{\circ} \mathrm{C} \quad T \geq 44^{\circ} \mathrm{C}
\end{array}\right.
$$


$\mathrm{f}(\mathrm{W})$ water reversionary function

$$
\begin{gathered}
f(W)=\left\{\begin{array}{cc}
\frac{(1-C) R}{E T_{m}} & 0<(1-C) R<E T_{m} \\
0 & (1-C) R \geq E T_{m}
\end{array}\right. \\
E T_{m}=k_{c} E T_{0}
\end{gathered}
$$

$\mathrm{R}$ is precipitation, $\mathrm{C}$ is runoff coefficient, ETm is crop water requirement, ET0 is reference evapotranspiration, $\mathrm{Kc}$ is crop coefficient.

ET0 was calculated by modified Penman equation.

\subsection{Index for Soil Suitability Evaluation}

Some soil elements that influenced crop production such as organic mater, total nitrogen, available $\mathrm{N}$, available $\mathrm{P}$, depth of soil body, depth of black earth, terrain and soil texture were derived to evaluate the suitability of soil. The range of each element is divided into 3-5 level scales on the basis of their degrees of suitability or limitations to the crop growth. The different levels are defined as follows:

- Level 5: the characteristic (quality) is optimal for crop growth.

- Level 4: the characteristic is nearly optimal for crop production.

- Level 3: the characteristic has moderate influence on yield decrease and benefits can still be made.

- Level 2: the characteristic decrease the yield and the land becomes marginal for crop growth.

- Level 1: the characteristic may prohibit the use of soil for crop cultivation.

The suitability of each soil unit was evaluated on the basis of soil fertility composite index, which accumulates all the level numbers of each element of this soil unit. The higher the accumulated numerical value is, the more suitable the soil is for crop growth.

\subsection{Land Evaluation Methods}

\subsubsection{Classification of Climatic Suitability}

Corresponding to each meteorological station, there is a numeric value of climatic potential productivity calculated. Classification of climatic potential productivity was made using spatial interpolation method and a classification map was formed in geographical information system. The map indicated that the region with high value had more suitable climate for crop growth.

\subsubsection{Classification of Soil Suitability}

For large scale area, complex landform and soil quality determined that there are big differences among the suitability of soil units. The problem is how to classify soil units according to their fertility. The methods we used were: first, to form the polygon map of soil fertility composite index on the basis of soil type map by calculating soil fertility composite index of each soil unit in GIS platform. Next, segment the study area by rectangular grid of a certain size. The size of grid was determined by the scale 
of the study area and research objective. Then, calculate the weighted average soil composite fertility index of each grid taking the area of the soil with different types in the grid as weighting, and assign the value of the average fertility on the center of the grid. Finally, form the map of soil suitability classification on the basis of the values of fertility in each grid by spatial interpolation method.

\subsubsection{Synthetical Evaluation of Land Suitability}

Overlay the climatic and soil suitability map to synthetically evaluate the land suitability.

The GIS platforms used were Arcview 3.2 and ArcGIS 9.0.

\section{Case Study}

\subsection{Study Area}

Jilin province is located in the central part of northeast $\operatorname{China}\left(122-131^{\circ} \mathrm{E}, 41-46^{\circ} \mathrm{N}\right)$, covering the area of 187,400 square kilometers, The eastern part of the province is the mountainous area of the Changbai Mountains with an elevation of over 1,000 meters and the Jidong hilly land about 500 meters above sea level. The western part of the province is the Songliao Plain, whose low and level western section is the grain producing area of the province. The soil type changes from dark-brown earth, black soil to chernozem from east to west. The annual time of sunshine is 2,200-3,000 hours. The annual average effective accumulated temperature is $2,700-3,600^{\circ} \mathrm{C}$. The precipitation of the province in a year is $550-910 \mathrm{~mm}$ and the frost-free period lasts 120-160 days. Jilin is one of the most important commodity grain producing areas in China. It abounds with soybean, corn, sorghum, millet, rice, small red bean, wheat, tuber, sunflower seed, beet and tobacco.

\subsection{Data}

1:500,000 soil map and attribute data were provided by Soil and Fertilizer Station of Jinlin Province. The data of crop yield, planting area of 30 years in each county were obtained from Statistics Bureau of Jilin Province. Meteorological data of precipitation, temperature, wind speed and sunshine hours from 1980 to 2006 in 46 meteorological stations were provided by Meteorological Bureau of Jilin Province.

\subsection{Result}

\subsubsection{Climatic Suitability Evaluation}

The value selection of the parameters in the photosynthetic productivity calculation formula were as follows $[2,3,4]$ :

$\varepsilon=0.49, \alpha=0.48, \rho=0.10, \gamma=0.01, \Phi=0.224, \omega=0.30, \mathrm{X}=0.08, \mathrm{H}=0.14$

Y. Shan calculated the water requirements of maize in the Bajiazui irrigation area in Qingyang city, Gansu Province. Modified Penman equation was used to calculate reference evapotranspiration, and crop coefficient Kc was obtained by experiment[2]. Compared with the test result, the result calculated by penman equation was more 
accurate than that of the other methods. We used this value of $\mathrm{Kc}$ in this research to calculate water requirements.

Climatic potential productivity was calculated using the methods mentioned above. The higher the value of climatic potential productivity was, the more suitable the climate was for crop growing. The classification of climatic suitability in Jilin Province was made by equally dividing the range of the numerical value of climatic potential productivity of all counties into 8 level and mapping in GIS software. The evaluation map is presented in Fig. 1.

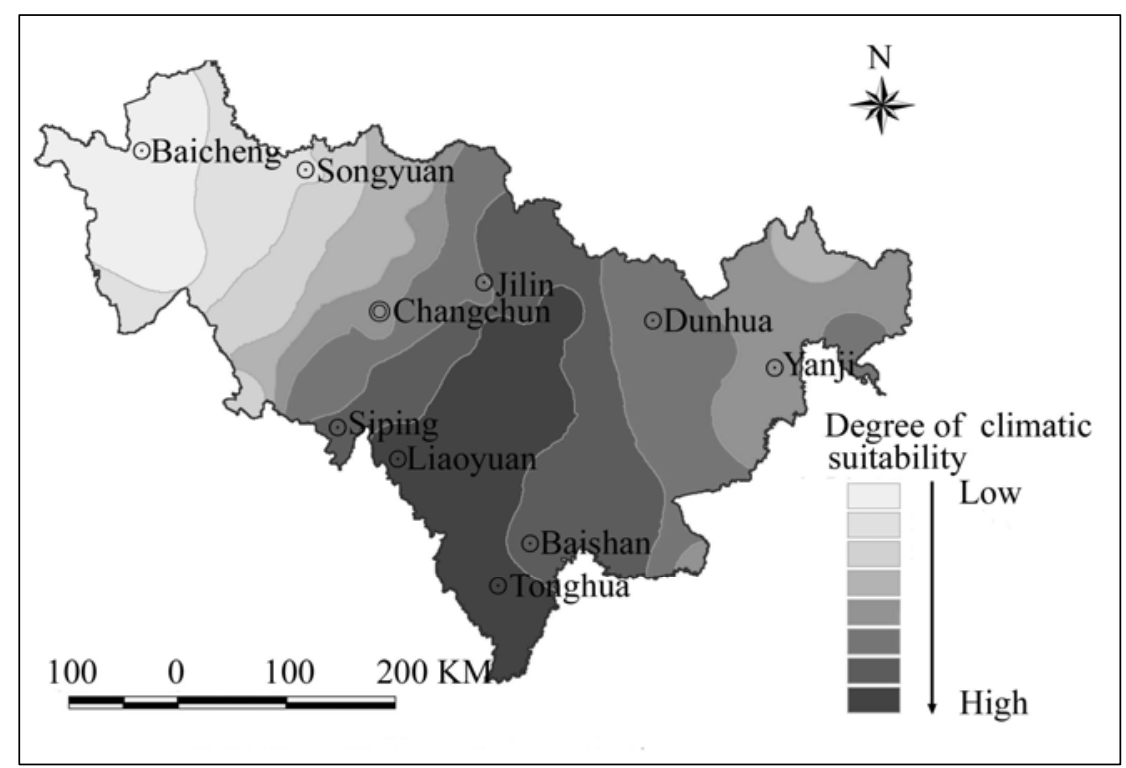

Fig. 1. Classification of climatic suitability for maize production in Jilin Province

From the view of climatic conditions, mid-eastern Jilin Province is the most suitable region for maize production, including most part of Ji'an, Tonghua, Liuhe, Meihekou, Dongfeng, Liaoyuan County and a part of Yongji and Jiaohe County. Light, heat and water resources are abundant in the farming season in this region. The climatic suitability gradually decreases from this region to the east and the west region respectively. The eastern part of Jilin Province is full of water resources, but is lack of light and heat resources. Maize production in the western part is restricted by the water condition despite the abundance of light and heat resources.

\subsubsection{Soil Suitability Evaluation}

Soil elements which influence crop production were used to analyze soil fertility, including: organic mater, total nitrogen, available $\mathrm{N}$, available $\mathrm{P}$, depth of soil body, depth of black earth, thickness of strata feature, terrain, soil texture, soil moisture, obstacle factors, soil erosion, and unit production. The irrigation was not taken into consideration because maize planting is rainfed in Jilin Province. The different level scales of suitability or limitation were defined in table 1[6]. 
Table 1. Definition of level scale of soil evalution elements

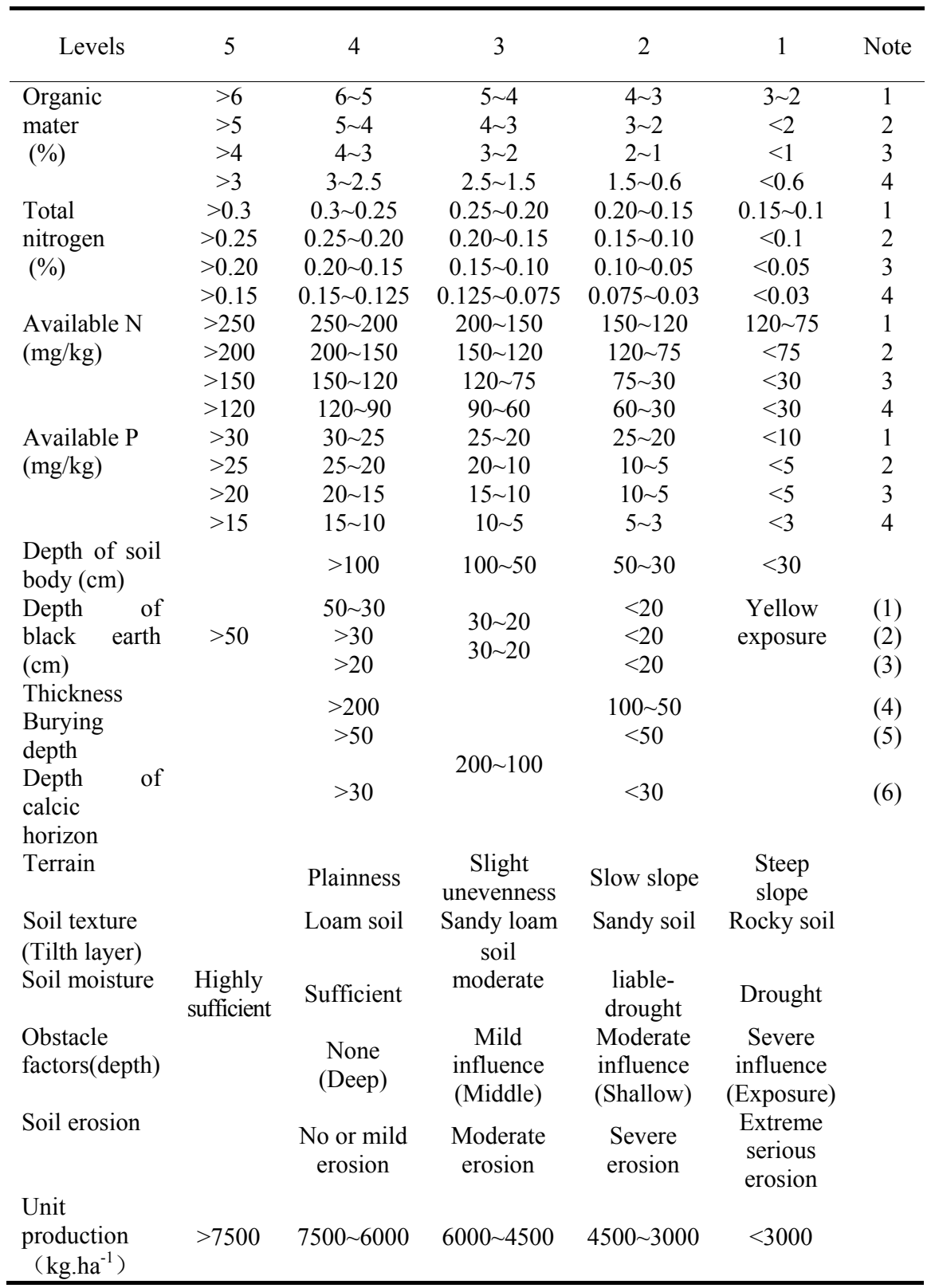

Note: 1 Eastern cold and humid mountain area

2 Eastern warm and humid semi-mountainous area

3 Central semi-humid liable-drought plateau area

4 Western semi-humid semiarid plain area 
(1) Black soil, chernozem, meadow brown soil, and paddy soil

(2) Albic soil, aeolian sandy soil

(3)Dark-brown earth

(4) Peat soil

(5) Swampy soil, bury peat soil

(6) Chestnut soil

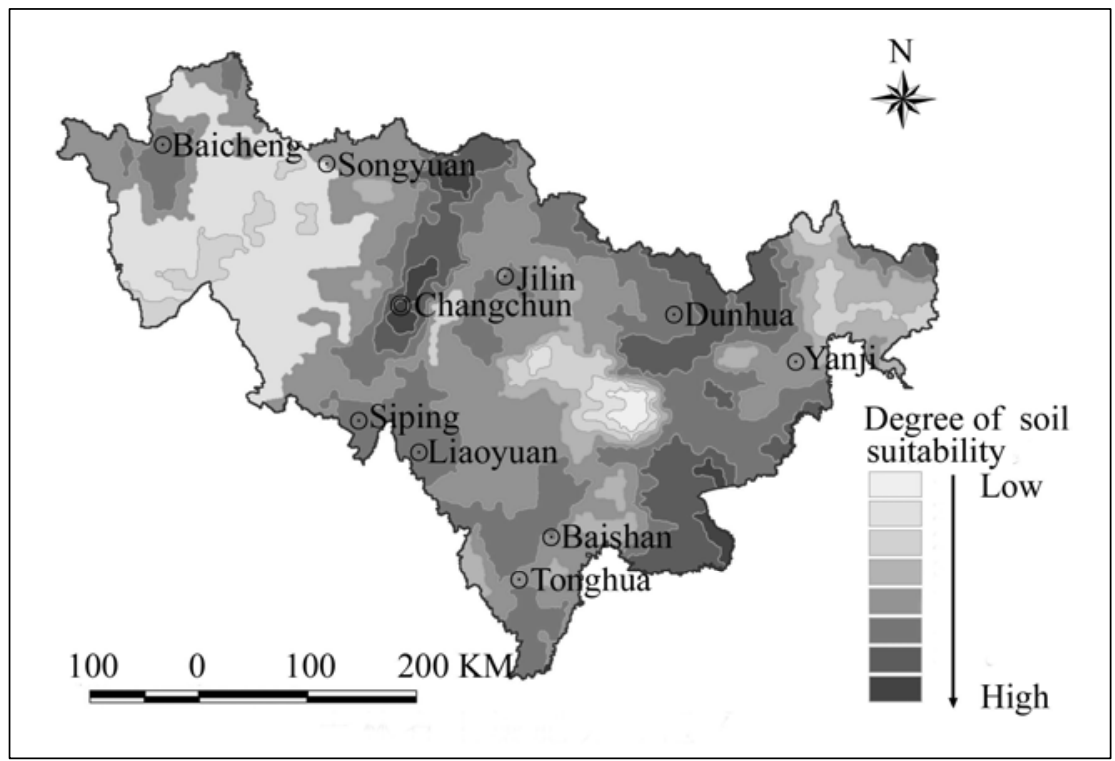

Fig. 2. Classification of soil suitability for maize production in Jilin Province

Soil suitability was divided into 8 levels on the basis of soil fertility composite index in Jilin Province. The evaluation result was presented in Fig. 2. The most suitable region for maize production expresses zonary distribution from Yushu, Nong'an to Changchun in Jilin Province. In general, the soil in the eastern humid semimountainous area and the western part of central semi-humid liable-drought plateau area, with sufficient or moderate soil moisture, plain or slightly uneven terrain, thick soil body and black earth, no or mild erosion and rich nutrients, is suitable for maize production. In the eastern part of central semi-humid liable-drought plateau area, soil is moderately eroded and the soil nutrients in these areas are less nourishing than those in the region mentioned above. In the western semi-humid semiarid transition plain region and semiarid plain region, the surface soil is liable to erosion and black earth layer is thin due to the rugged or long gentle slope terrain, and soil condition restricts crop production.

\subsubsection{Synthetical Evaluation of Land Suitability}

Mapping land suitability for maize production was made by overlaying the climatic and soil suitability in GIS platform. Result of evaluation was presented in Fig. 3. 


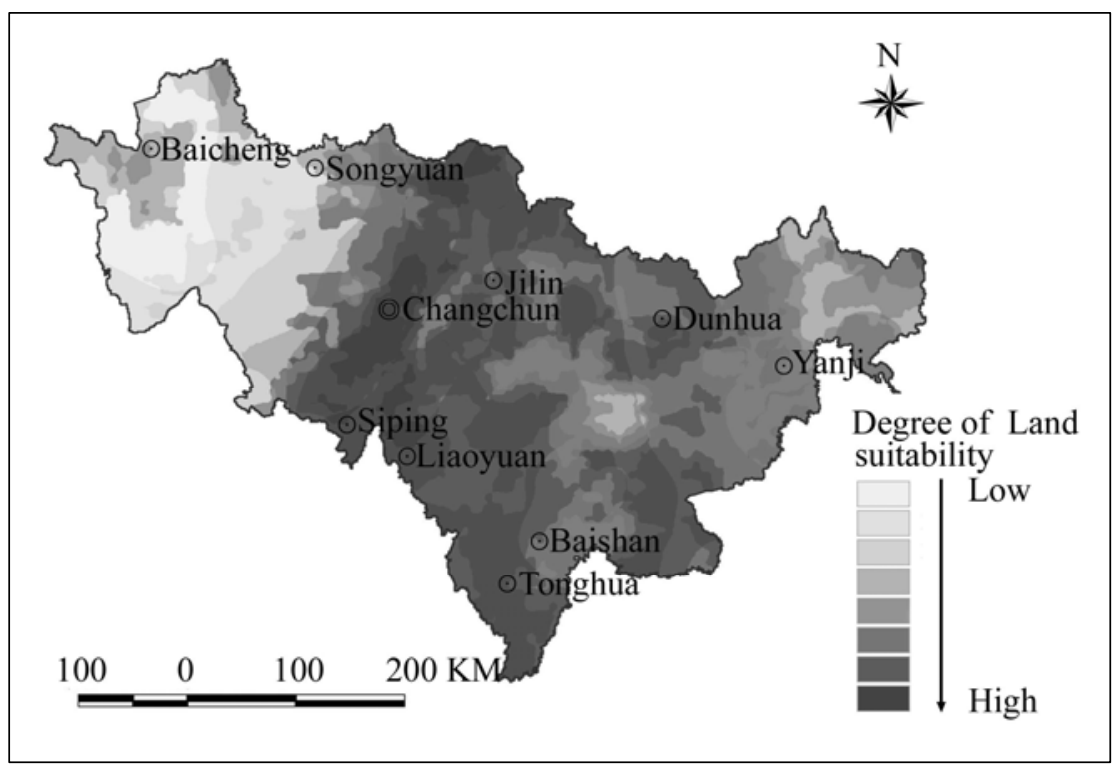

Fig. 3. Classification of ecological suitability for maize production in Jilin province

Ecological condition is suitable for maize growth in the central part and mideastern part of Jilin Province. Light, heat and water resource are rich in the maize growing season. Soil condition satisfies the need for maize growth. In fact, there are several national commodity grain bases in the region. Most of eastern mountain area is covered with forest because the cool and cold climate is not suitable for crop cultivation. In the western part of Jilin Province, the poor soil condition and deficiency of water restrict the utility of light and heat resources, therefore the ecological condition is unsuitable for maize production.

\section{Conclusion}

Comparing with the crop yield map which is based on the statistical yield of 30 years in each county, the result of ecological suitability assessment is approximately consistent with the yield. Crop production is determined by two major aspects, the aspect of land physical resources such as soil, topography, and climate, and the aspect of socioeconomic resources such as management level, market position, and other human activities. The former are relatively stable properties, while the latter are much more variable and dependent on social and political decisions (E. Van Ranst et al., 1991). This method is feasible to assess the ecological suitability in the region. More socioeconomic factors should be taken consideration during crop structure arrangement. 
The crop climatic potential productivity (photo-temperature-water potential productivity) is the highest theoretical productivity of the crop when crop makes full use of the present climatic resources in this area with the most appropriate technology and managerial techniques. The climatic productivity could properly evaluate the climatic suitability for crop growth by establishing the relationship between crop product and the light, heat and water resources.

Analyzing spatial data in large scale area, it is difficult to extract the regularity among data due to the complexity of distribution of spatial attribute. Geographic information system is increasingly applied in the analysis of complex spatial data by its powerful function of data management, spatial analysis and graphics display. In this research, grid segmentation method is used to extract the regularity of soil fertility in large area in GIS. The analysis result is more rational and reliable.

In the paper an approach to assess the ecological suitability of land is suggested. Parameters in the method such as crop coefficient, grid size and the number of classification grades should be adjusted according to the crop species, scale of area and purpose of analysis.

Acknowledgements. Research funded by project from STCSM (08DZ2210600, 08QA14058) and National Key Technology R \& D Program (2008BAD96B01). Many thanks to the staff in Soil and Fertilizer Station, Meteorological Bureau, Jilin Province for providing soil and meteorological data.

\section{References}

1. Van Ranst, E., Debaveye, J.: Land Evaluation Part I, Principles in Land Evaluation and Crop Production Calculation. Agricultural Publication. No. 7. Brussels, Belgium: General Administration for development cooperation (1991)

2. Shan, Y., Zhang, X., Chen, L.: Application of Penman Equation in Reference of Crop Water Requirements. Journal of Anhui Agri. Sci. 36(10), 4196-4197 (2008)

3. Guo, J., Gao, S., Pan, Y.: Study on Crop climatic potential productivity and the measures of its development and utilization in northeast China. Meteorology 21(2), 3-6 (1995)

4. Gurforch, H.W., Shay Kewich, C.F.: A Temperature Response Function for Corn Development. Agric. for Meteorol. 50, 159-171 (1990)

5. Deng, G.: Study on Light and Temperature Resources and Climatic Productivity of China. Natural resources (April 1980)

6. Soil and fertility station, Jilin province. Soil in Jilin Province. China Agricultural Press (1998)

7. Geerts, S., Raes, D., Garcia, M., Del Castillo, C., Buytaert, W.: Agro-climatic Suitability Mapping for Crop Production in the Bolivian Altiplano. Agricultural and Forest Meteorology 139, 399-412 (2006)

8. Qiu, B., Zhou, Y., Li, X.: Dynamic Assessment of Regional Land Resource Suitability Based on Geographical Information System. Acta Pedologica Sinica 39(3), 301-306 (2002)

9. Dai, Q., Liu, M., Wang, Y., Liu, G.: Land use Adaptability Evaluation and Potential Capability Analysis of Hilly Region in Northeast China. Bulletin of Soil and Water Conservation 23(1), 27-31 (2003) 
10. Wang, F., Xing, S.: Progress in the Research on Regional Agricultural Land Suitability Evaluation. Agriculture Network Information 1, 32-34 (2006)

11. Yu, J., Nie, Y., Zhou, Y., He, Y.: Niche-fitness Theory And its Application to GIS-based Multi-suitability Evaluation of Cultivated Land. Acta Pedologica Sinica 43(2), 190-196 (2006)

12. Zhang, J., Feng, J., Bian, X., Zang, M., Hu, D.: Variable Weight Approach in Evaluation of Crops Ecological Adaptability. Journal of Nanjing Agricultural University 29(1), 13-17 (2006)

13. Du, H.y., Li, J.: Agricultural Land Suitability Evaluation. Model and System Implementation-A Case Study of Panzhihua. Resources Science 23(5), 41-45 (2001) 